\title{
Abies alba Oil
}

National Cancer Institute

\section{Source}

National Cancer Institute. Abies alba Oil. NCI Thesaurus. Code C72185.

The essential oil from the needles of Abies alba. Abies alba oil is used for its aromatic properties and as a treatment for respiratory system illnesses. 